\title{
Comprehensive evaluation model for Smart Growth
}

\author{
Chenyang Li \\ School of North China Electric Power University, Baoding 071000, China \\ 1572371776@qq.com
}

Keywords: Smart growth, evaluation system, multi-objective programming model

\begin{abstract}
With continued urban sprawling and the loss of farmland, urban planning has become increasingly important and necessary. And Smart growth focuses on building cities that embrace the sustainability, so it is useful to explore the theory and implement it into city design. Here we establish a complete evaluation system to evaluate the degree of Smart growth and the development plan of a city. Some main indicators are arranged into different levels for quantitative analysis and then we establish multi-objective programming model to compare the plans in order to distinguish from the good and the bad one. Using our method, good results all have been achieved, and finally we give our own explanation.
\end{abstract}

\section{Introduction}

Smart growth is an urban planning theory that originated in 1990's as a means to curb continued urban sprawl and reduce the loss of farmland surrounding urban centers. Since the 1990s, many urban areas have encouraged the development of planned communities in which people can live, shop, work, go to school, worship, and recreate without having to travel great distances by automobile, a lot of people have benefit from this method.

It is an approach to development that encourages a mix of building types and uses, diverse housing and transportation options, development within existing neighborhoods, and community engagement [1].

When communities choose smart growth strategies, they can create new neighborhoods and maintain existing ones that are attractive, convenient, safe, and healthy. They can foster design that encourages social, civic, and physical activity. They can protect the environment while simulating economic growth ${ }^{[2]}$.

\section{Model building}

\subsection{Analysis of the problem}

Until now, there is no uniform standard for the evaluation of smart growth, different research organization has given their own evaluation method about the growth of a city from different view. The most representative is Glaster and Hanson ${ }^{[3]}$ use eight indicators to evaluate the level of Smart Growth, and they are: Density, Continuity, Concentration, Clustering, Centrality, Nuclearity, Mixed use and Proximity.

Smart growth focuses on building cities that embrace the E's of sustainability-economically prosperous, socially Equitable, and Environmentally Sustainable. And it has ten principles:

1. Mix land uses

2. Take advantage of compact building design

3. Create a range of housing opportunities and choices

4. Create walkable neighborhoods

5. Foster distinctive, attractive communities with a strong sense of place

6. Preserve open space, farmland, natural beauty, and critical environmental areas

7. Strengthen and direct development towards existing communities

8. Provide a variety of transportation choices 
9. Make development decisions predictable, fair, and cost effective

10. Encourage community and stakeholder collaboration in development decisions

If we want to define a metric to measure the success of Smart growth, we have to consider the three E's and its 10 principles. Considering the evaluation system above and combine the availability and effectiveness of data, we can build our system to evaluate.

\subsection{Evaluation model}

We establish our system for the evaluating the level of Smart growth of a city, so environment, living, transportation, culture and economy should be included.

Smart Growth originated as a mean to curb continued urban sprawl and reduce the loss of farmland surrounding urban centers, we take the direct goals and the evaluation criteria of different departments and experts then can build a multilevel index evaluation method. The evaluation indicators can be divided into 3 levels.

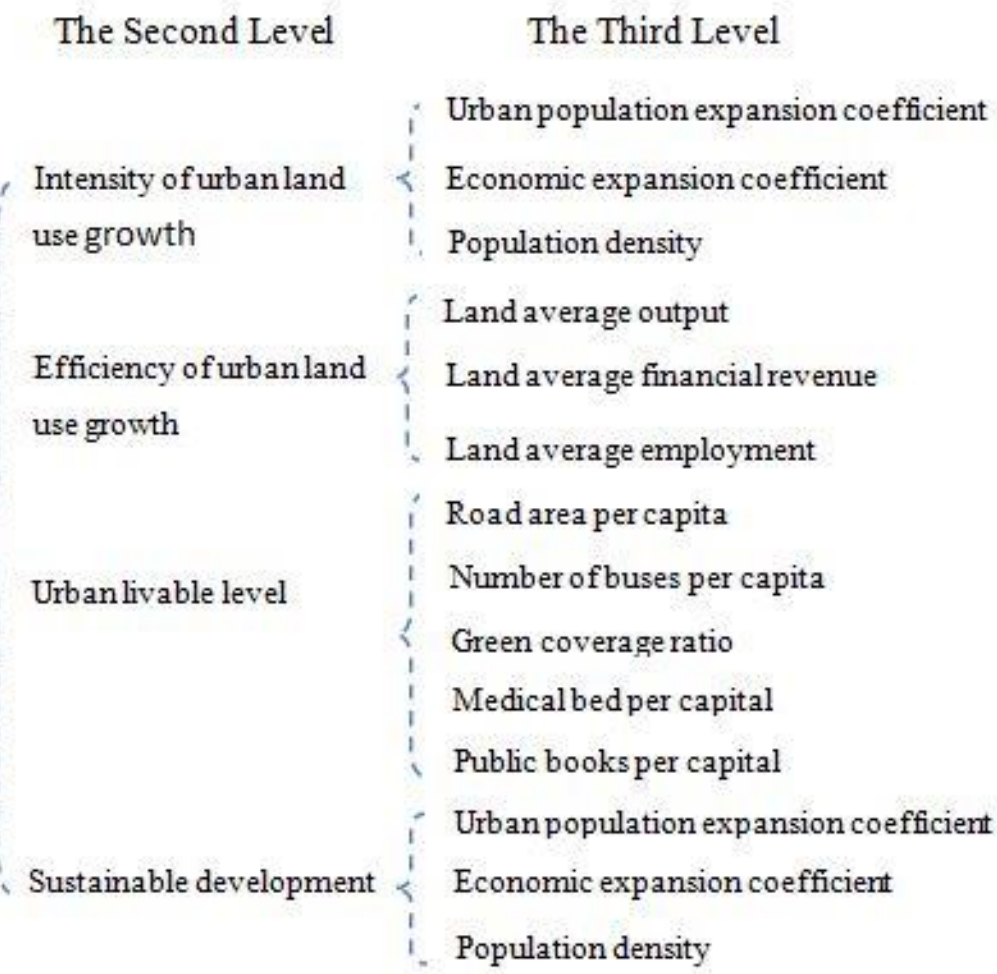

Fig. 1 Indicators in two levels

We adopt internationally popular Delphi method to determine the relationship between the indicators at the same time level ${ }^{[4]}$. based on the method, and we combine the results of some experts doing well in city planning and land policy, using the following formula we can calculate the weight of each indicator.

$W=\frac{\sum_{j=1}^{n} E_{i j}}{n}$

$W$ - The weight of indicators;

Eij_- The score expert $j$ gives the indicator $i$;

$n$ - The number of experts

Except for considering the direct impact of some factors, we also obey the following principles, they are: Science, Comprehensiveness, Feasibility, Sustainability.

\subsection{Multi-objective programming model}

For development plans of each city, we need to compare the pros and cons of these plans, and then evaluate the success of them. That's to say, all factors that affect development need to be considered as fully as possible. So here we establish a multi-objective programming model. Here we apply 15 indicators in evaluation model (2.1), they are defined $x 1-x 15$. The grey multi-objective dynamic 
programming model aims to the best economic benefit, the best social benefit and the best ecological benefit. Based on the three benefit objective principle, we can get:

$$
\begin{array}{ll}
\max \left\{\otimes\left(C_{i}\right) X\right\} \\
\text { s.t. } \quad \otimes(a) X \leq \otimes(b) ; \\
\quad X \geq 0, \quad i=1,2, \cdots k
\end{array}
$$

In which, max is the objective function, aij and bi are restraint coefficient and constraint constant of the equation. Grey number is a set expressed with ${ }^{\otimes}$.

We define the function of economic benefit, social benefit and ecological benefit are $f(x), g(x), h(x)$. So the corresponding $\max f(x)$, max $g(x)$ and max $h(x)$ represent the best economic benefit, the best social benefit and the best ecological benefit. Then we can use $G M(1,1)$ model to forecast and get the whiting value.

\section{Model application}

After establishing our evaluation system, we need to choose practical examples to verify the correctness and efficiency of our model. To demonstrate the versatility of the model, we ended up choosing two cities in different continents, and they are: Ma'anshan, Ilorin.

First, we can easily get the current plan of the two cities from Bureau of Statistics ${ }^{[5]-~[7]}$. In order to make the results more reliable and more convenient to compare we choose another city for contrasting, then we determine the city East Liberty as a good example, East Liberty is a model city of Smart growth.

Delphi method is used to determine the weight of each indicator. Then we eliminate the impact of units, and the results expected are multiplied by the corresponding weight of indicators. Finally we can get score of each indicator in different levels.

Table 1 Score of cities

\begin{tabular}{cccccc}
\hline \multirow{2}{*}{ City } & \multicolumn{4}{c}{ The 2nd level } & \multicolumn{2}{c}{ The 1st } \\
& $A$ & $B$ & $C$ & $D$ & level \\
\hline Ma'anshan & 0.9187 & 0.7141 & 0.6211 & 0.6382 & 0.6887 \\
East Liberty & 1.4974 & 1.2997 & 1.1276 & 1.7786 & 1.3574 \\
Ilorin & 0.5838 & 0.9862 & 1.2513 & 0.5833 & 0.9539 \\
\hline
\end{tabular}

In the Table 1, $A$ stands for Intensity of urban land use growth; $B$ stands for Efficiency of urban land use growth; $C$ stands for Urban livable level and $D$ stands for Sustainable development.

According to the calculated results of indicators of all levels we know, the Smart Growth coefficient of Ma'anshan is 0.6887 , which is lower than 0.9539 of Ilorin. Among the score of the third level in the two areas, Ilorin has 8 higher than Ma'anshan. Ma'anshan is higher than Ilorin in economic expansion, utilization of land resources and energy consumption elasticity, we think the situation is connected with its steel industry. And then Ilorin is higher than Ma'anshan in the factors of Efficiency of urban land use growth, we think it relies on the good land use policy of Ilorin. Ilorin also goes ahead in medical bed and public books, we have reasons that the service industry in Ilorin is better than Ma'anshan. In order to measure the degree of success, we take East Liberty for example, and we have much confidence that the degree of success of current development plan of Ma'anshan and Ilorin are $51 \%$ and $70 \%$ respectively.

Seeing from the results that Ma'anshan and Ilorin is weak in some different indicators, the growth situation of them needs to be improved, then we can make our macro plan for them.

We regard the growth plan for a city as a huge system, and because of its complexity, grey characteristic, multi objective, dynamic characteristic and controllability, we can take it as a grey system. Then we can use our Grey multi-objective dynamic programming model to evaluate the growth plan of two cities. Through $G M(1,1)$ model and combine qualitative analysis, finally we get the coefficient of $f(x), g(x)$ and $h(x)$. 
Next we establish the constraint condition for the objective function. The constraint condition is different for the two areas, we discuss the situation of Ma'anshan first.

1. As for Smart Growth, we hope the value of index can be promoted after changing, so the constraint condition can be expressed as follows: $\sum_{i=1}^{n} a_{i} x_{i}>0.689 \quad \mathrm{n}=15$

2. Relationship between expected growth:

1) The constraint of ration of economy and population expansion coefficient: $X_{1} / X_{2}>1.929$

2) Relationship between population density and the employment: $0.65 S \bullet x_{3}>x_{6}$

$S$ : the urban land area

3) Population growth rate: $70.69 X_{3}<800000$

4) Economic development bottom line: $\begin{aligned} & X_{4}>7 X_{5} \\ & X_{4}>5.7\end{aligned}$

3. Land structure and Resource allocation

1) Greening rate: $0.1<X_{9}<0.7$

2) Road are per capital: $X_{7}<30$

3) Non construction land area: $X_{15}>0.18$

$X_{15}+X_{12}=1$

4) Energy consumption elasticity coefficient: $X_{13}<13$

5) Elasticity coefficient of industrial output value and land use: $X_{14}>0.83$

The same analysis process, we can get the constraint conditions of Ilorin are listed:

$$
\left\{\begin{array}{l}
\sum_{i=1}^{n} a_{i} x_{i}>0.954 \\
X_{1} / X_{2}>1.725 \\
0.65 S \cdot x_{3}>x_{6} \\
85.6 x_{3}<500000 \\
x_{4}>7 x_{5} \\
x 4>7.26 \\
0.3<x_{9}<0.6 \\
x_{7}<30 \\
x_{15}>0.1 \\
x_{15}+x_{12}=1 \\
x_{13}<1.7 \\
x_{14}>0.64
\end{array}\right.
$$

After establishing our Grey dynamic programming model, we use Lingo to calculate the results. Finally we picked out three sets of solutions from all the calculation results. The plans named A, B, C contain the best economic benefit and the best ecological benefit respectively. Based on the constraint condition, our final plan all takes geography, expected growth rates, and economic opportunities into account. Comparison of current plan and the three best benefit plan are in Fig. 2. 


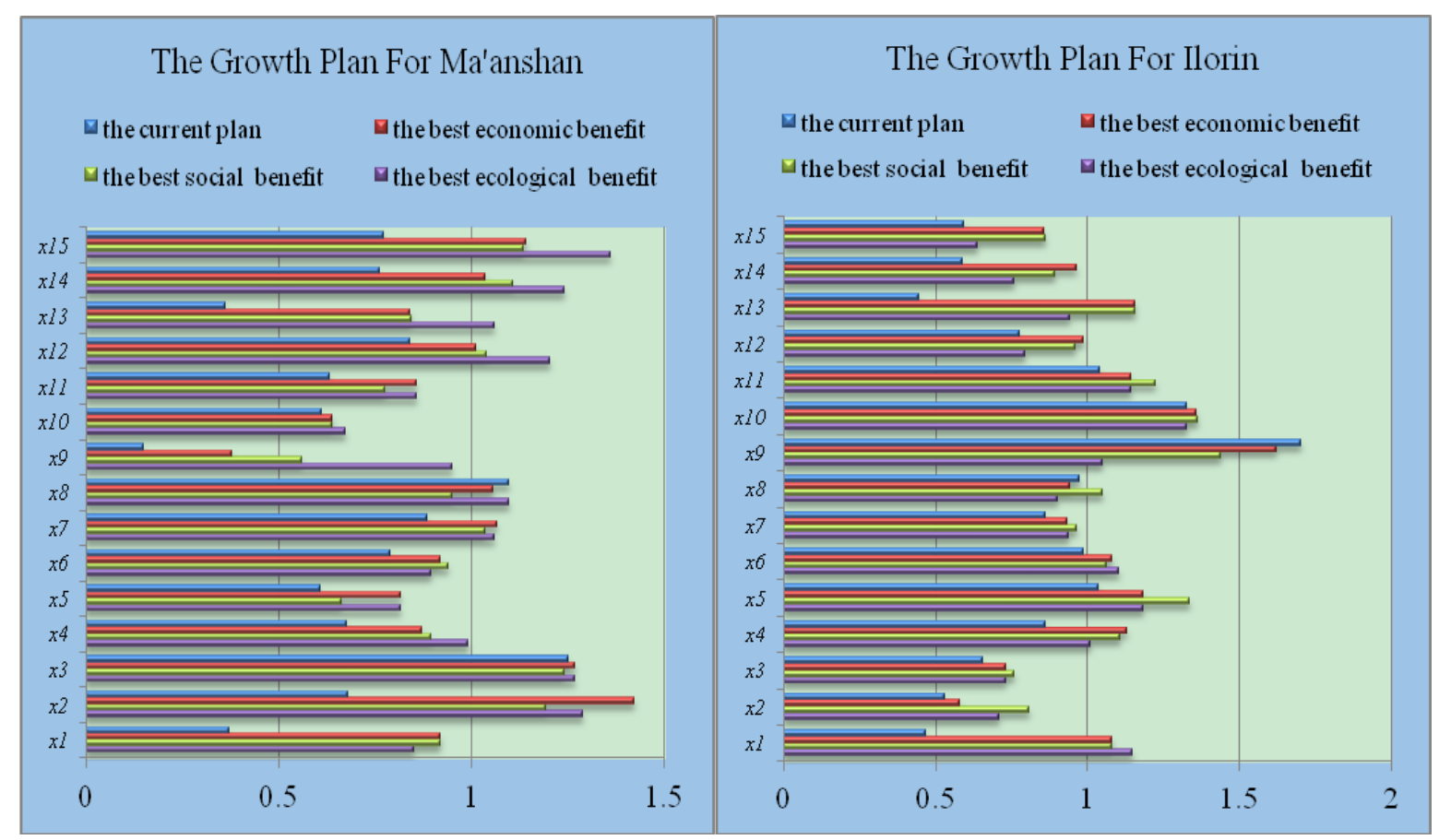

Fig. 2 Plan comparison

\section{Conclusion}

From the comparison of current plan and the three best benefit plan, we can see that after optimization, the score of indicators in latter all get promoted, which proves the positive effect of our plan.

According to the value of Smart growth coefficient, we calculate the degree of success of plan rise up $11 \%, 14 \%$, and $17 \%$ in Ma'anshan, and the percentage are $11 \%, 12 \%$, and $3 \%$.

In this paper, we present a metric to measure the success of smart growth of a city. And we have argued that it has strong versatility and scalability. Based on the smart growth principles, we have developed a growth plan to introduce a series of potential initiatives in detail from different aspects. Validated through the data of the city we selected, we can find that the initiatives do make the growth of the city smarter.

While the development of a city is highly dynamic, the compiling method of urban master planning must adapt to the increasing uncertainty of city development prospect accompanied by the increasing of uncertain factors in urban growth. In the future, how to face a flood of opportunities and challenges in the process of the urban development is the main question that needs further discussion.

\section{References}

[1]. Smart Growth: Improving lives by improving communities. https://smartgrowthamerica.org/

[2]. EPA, This is Smart Growth.” 2016, https://www.epa.gov/smartgrowth/smart-growth-publication

[3]. Galster G, Hanson R, Ratcliffe M R, et al. wrestling sprawl to the ground: defining and measuring an elusive concept [J]. Housing policy debate, 2001, 12 (4): 681-717

[4]. Cheng Maoji. Research on the evaluation and optimization of urban growth in Nanjing based on Smart Growth [D]. Nanjing Normal University, 2012.

[5]. Anhui statistical yearbook, Retrieved from: http://www.ahtjj.gov.cn/tjj/web/index.jsp

[6]. Kwara Database, http://www.kwarastate.gov.ng/

[7]. BEA Database, https://www.bea.gov/ 